\title{
Knowing the Good and Knowing What One Is Doing
}

\author{
SERGIO TENENBAUM
}

\section{Introduction}

Most contemporary action theorists accept - or at least find plausible - a belief condition on intention (especially on intention in action) and a knowledge condition on intentional action. The belief condition says that I can only intend to $\phi$ if I believe that I will $\phi$ or am $\phi$-ing, and the knowledge condition says that I am only intentionally $\phi$-ing if I know that I am $\phi$-ing. The belief condition in intention and the knowledge condition in action go hand in hand. After all, if intending implies belief, and if $\phi$-ing intentionally implies intending to $\phi, r^{2}$ then in $\phi$-ing, I intend to be $\phi$-ing, and, by the belief condition, I believe that I am $\phi$-ing, and if this belief is justified, and we are not in a Gettier situation, etc., then, I will also satisfy the knowledge condition. Moreover, the claim that when intentions properly result in action, the corresponding belief constitutes knowledge is a relatively safe assumption, at least as an assumption about what it is generally the case. For it would be strange if an action theorist wedded to the belief condition were to think that the belief in question would be unjustified, or that the justification in question would not be

1 Thanks to Rachel Barney, David Hunter, Jennifer Nagel, David Velleman, and the participants of the Guise of the Good workshop at Colgate University and of the Belief and Agency workshop for very helpful comments on earlier drafts of this paper.

2 Of course, one can resist this argument at many points; some of these issues will be raised below. 
sufficient for knowledge at least when the intention and the action were not related in deviant ways. ${ }^{3}$

These are, of course, rough statements of the view. As more and more crafty counterexamples hit the airwaves, subtle modifications, caveats, and conditions are added to these conditions. The modified versions might seem like frail cousins of the original bold claims, but they gain sympathy from the fact that there appears to be something profoundly true about these conditions. After all, immune to the ingenuity of philosophers seems to be the obvious fact that in the normal course of events, intentions to $\phi$ and beliefs that one is $\phi$-ing, as well as $\phi$-ing intentionally and knowing that one is $\phi$-ing seem to be found together.

I don't intend here to add to the chorus of those who defend these conditions or to engage for too long in the finding of further counterexamples to these conditions (although I'll spend some time on these tasks). My concern is not directly with the knowledge or belief conditions but more specifically with what they can tell us about a thesis I hold dear: the guise of the good thesis, or, as I prefer to call it a "scholastic view" of action and action explanation. I am concerned in particular with two worries that these conditions can raise for a scholastic view. The first concern is that the scholastic view gives the wrong account of practical knowledge; practical knowledge, on this view, is not knowledge of the good but knowledge of what one is doing. Second, one might think that the scholastic view cannot account for an essential feature of intentional actions; namely, that acting satisfies the belief or the knowledge condition. The aim of this paper is to explain how the scholastic view can account for these conditions and, more generally, to explain why the scholastic view is particularly well-placed to explain these conditions in the right way.

Let us define (roughly for now) two views:

3 This is not to say that it is easy to explain how such knowledge is justified. For an influential proposal, see Velleman (1989). For a more recent proposal, see Setiya (2008). 
Reflectivism - An agent intentionally $\phi$-es only if he knows (without observation and in the particular way in which actions are known ${ }^{4}$ ) that he is $\phi$-ing and an agent intends to $\phi$ if an only if he believes (not on the basis of evidence) that he will $\phi$.

Scholastic View - An agent is intentionally $\phi$-ing if and only if he judges his $\phi$-ing (right now) to be good and an agent intends to $\phi$ if and only if he judges that it is / will be good to $\phi$.

The two views are not obviously incompatible, but Setiya points out a problem for those who want to hold on to both these views. If the scholastic view does not imply reflectivism or vice-versa, one will now be committed to an unexplained necessary relation between two properties. $^{5}$

Whatever one thinks about the plausibility of unexplained necessary relations, there seems to be a much more general problem that the knowledge conditions raise for scholastic views. The claim that the scholastic view gives an overly demanding account of intentional action is a common criticism; opponents of the scholastic view tend to think that it defines out of existence a large range of intentional actions. ${ }^{6}$ But the claim that the scholastic view is too demanding seems to imply that there must be a way of understanding intentional actions that imposes fewer requirements on what counts as an intentional action. Thus looking at views that impose very minimal requirements would be a natural avenue to pursue in light of these criticisms.

4 This clause is vague so that we can allow for a number of accounts of what is special about the way we know our actions in this view. In the traditional Anscombean view, knowledge of one's body is also knowledge without observation.

5 Setiya puts the point slightly differently; according to Setiya, a good theory of intentional action must explain why the belief condition is necessarily true, and views that accept the guise of the good thesis cannot explain this necessity (Setiya 2007, esp. 39-48). But I take it that this is just a different way of making the same point. Since we already know that the belief condition is a necessary truth about intentional action, not being able to explain it leaves us with an unexplained necessary relation between two properties exemplified by intentional actions.

6 For two influential versions of this complaint, see Velleman (1992) and Stocker (1979). 
And, to the extent that we can show that such minimal views cannot account for important features of agency, we can make more plausible the claim that the scholastic view does capture the full range of intentional action. ${ }^{7}$

It is worth starting by defining such a minimal alternative to the scholastic view, an alternative that can be dubbed "Pure Reflectivism." I will define pure reflectivism in a rather vague manner so as to allow as many views as possible to fall under this rubric:

Pure Reflectivism: A theory of intentional actions is a theory that explains the truth of reflectivism by characterizing actions or intentions in terms of the states that constitute the special knowledge one has of one's actions or intentions.

The central idea is that in explaining the truth of reflectivism, in explaining the special way in which we have knowledge of our actions, we have thereby provided a theory of intentional action. Moreover, any alleged property of intentional actions that is not needed for explaining reflectivism would be an accretion; it is not an essential property of intentional actions. Here are a couple of suggestions that would be versions of positions falling under this characterization of pure reflectivism. One could define the state of intention as some kind of motivating belief such that this special belief that I $\phi$ (right now) would, in the normal course of events, itself be that cause of my $\phi$-ing (right now). ${ }^{8}$ Another possibility to satisfy the pure reflectivist

7 Another obvious alternative to the scholastic view is to provide an account of actions in terms of mental states that are their causal antecedents and then provide a purely dispositional account of such states that does not make reference to any evaluative states. However, if these states are defined in terms of dispositions that ensure the truth of reflectivism, such an account would be an instance of pure reflectivism as defined below. If they aren't, then the account would seem be unable to account for an essential feature of agency. At any rate, the criticisms of pure reflectivism below would certainly extend to such accounts. For further criticisms of such views, see my Tenenbaum (2007).

8 This is loosely based on Setiya's account of intention in Setiya (2007). For a different view of this kind, see Velleman (1989). I discuss briefly in the last section how and whether the argument of the paper applies to Velleman's view. Although I do not follow closely Setiya's argument against the guise of the good thesis in 
constraint above would be to define an action as the self-determining consciousness of an explanatory nexus; that is, agency happens when one is conscious of $\phi$-ing by $\psi$-ing and the consciousness is itself what makes it the case that it is true that one is $\phi$-ing by $\psi$-ing. ${ }^{9}$

The scholastic view is, of course, not a pure reflectivist theory of agency. However, I want to argue, first, that (a modified version of) the scholastic view is not only compatible with any plausible version of the belief or knowledge condition, but even entails the truth of some version of reflectivism. This move would partially disarm Setiya's argument mentioned above; if I am right here, it is not true that the scholastic view needs to postulate two unrelated necessary truths about intentional actions. However, this is only a partial vindication. My initial argument, I concede, still leaves pure reflectivism as an attractive option; it will not yet show that we need anything beyond the knowledge and belief conditions to account for intentional actions. Thus in the final sections of the paper I try to show that pure reflectivism cannot fully account for important features of intentional actions. In particular, I want to argue that the scholastic view can, but pure reflectivism cannot, provide an explanation of Moore-paradoxlike phenomena in the practical realm.

\section{Practical Knowledge: Scholastic and Reflective}

Without much respect for the proper scholarly research, I will boldly assert that the predominant conception of practical knowledge for most of the history of philosophy has been that practical knowledge is

this paper, I hope it is clear that my formulation of the argument owes a great deal to Setiya $(2007 ; 2010)$.

9 This view is loosely inspired by Thompson (2008) and Anscombe (1963). Anscombe's view, however, does not fully satisfy the pure reflectivist constraint since she thinks that a proper answer to the question "why" must hit on an intelligible desirability characterization. I have argue that this aspect of Anscombe's view commits her to some version of the scholastic view in Tenenbaum (2007). Thompson's view is not, or at least not obviously, incompatible with the scholastic view. He does think that considerations of value are extraneous to a theory of action (Thompson 2008, 115), but this does not necessarily rule out the possibility that human action is possible only insofar as what we pursue is represented as good. 
knowledge of the good in the same way that theoretical knowledge is knowledge of the true. That is, to have practical knowledge is to know how to act well, to do the right thing in the right occasion for the right reasons. Practical knowledge in this view is the kind of knowledge that is expressed in the actions of the wise and the virtuous; it is the kind of knowledge expressed when one acts rightly. As theoretical success is a matter of arriving at the truth in the right way, practical success is, on this view, arriving at the good in the right way. This classical view of practical knowledge typically underwrites a commitment to the scholastic view. Insofar as the aim of theoretical and practical enquiries are, respectively, the true and the good, our theoretical and practical attitudes owe their form to this aim. Theoretical enquiry terminates in the fixation of belief; if such enquiry aims at truth, belief will then be our final stance regarding the truth of a certain matter. Thus to believe that $p$ is inter alia to be persuaded of the truth of $p$ or to hold $p$ to be true, or to have an all-out attitude endorsing the truth of $p .{ }^{10}$ Similarly, on the classic or the scholastic view, practical enquiry terminates in action, and thus action expresses one's final stance regarding what is good in a certain circumstance of choice. Acting thus is inter alia being persuaded of the goodness of $\phi$-ing or holding $\phi$-ing to be good.

Relatedly, just as theoretical attitudes such as belief express what the agent holds to be true even when the belief is false, the scholastic view claims that practical attitudes, such as intending, and acting itself, express what the agent holds to be good (I'll refer to those as "judgments of the good" or "evaluative judgments"), even when one intends and acts badly. Motivations for the scholastic view can vary, but, for our purposes, I'll suggest only one motivation that I take to be particularly important. One idea behind the scholastic view is that actions (and intentions) are exercises of a rational capacity, and that a rational capacity is essentially connected to its end, or, in other words, to that which an ideal exercise of the capacity would accomplish. The true and the good respectively refer simply to whatever the capacity would accomplish when properly exercised in ideal conditions. So if my theoretical capacities are properly exercised in ideal conditions, I'll acquire theoretical knowledge; that is, I'll arrive at knowledge of

10 This is obviously not supposed to be a full account of belief, and it is compatible with basically any more robust account of belief available. 
the truth. And, similarly, if my practical capacities are properly exercised in ideal conditions, I'll acquire practical knowledge; that is, I'll act well or my actions will (instrumentally or constitutively) bring about the good.

Of course, any version of the scholastic view needs to put forward a significantly less vague view than the one I am putting forward here. ${ }^{11}$ Since it is far from clear what it means to say that belief aims at the truth, or how (and whether) the truth is a standard of theoretical success, the assertion that the relation of the good to action or intention is the same in the practical realm cannot do more than inherit the obscurity of these views about the theoretical realm. But I hope this brief sketch and some further clarifications along the way will suffice for our aims.

Even this vague characterization, however, allows us to draw a contrast with a view of practical knowledge partly inspired by Anscombe's work. ${ }^{12}$ Anscombe argues that knowledge of our own actions is a species of a general kind of knowledge we have towards the body and its movements: knowledge without observation. The class of things known without observation extends more broadly than actions: according to Anscombe, we also know without observation the position of our limbs whether or not they are involved in our current actions. Whether or not we possess such knowledge without observation is the subject of much debate. Is Anscombe singling out proprioception as a special and mysterious form of knowledge? Is knowledge of the position of your limbs importantly different from the knowledge that there's a hallway behind my closed door? However, the claim that we know what we are doing without observation can survive many of the attacks launched at the broader view. For there is a form of basing for our knowledge of our own actions that seems to be absent from the other instances of the broader category of things that Anscombe claims to be known without observation. For in the case of knowledge of our own actions

11 I try to develop such a view in Tenenbaum (2007).

12 As I said above, I am not claiming that Anscombe is herself committed to a pure reflectivist view. In fact, I think that many of Anscombe's arguments can serve as justification for some of the central claims of the scholastic view. On this point, see Tenenbaum (2007). 
the knowledge tracks what we set ourselves to do; knowledge is, as in the old Thomist saying Anscombe quotes, the cause of what we understand. Without prejudging the issue of how we know our actions, the person who accepts that we have knowledge of our own actions can help herself to our whole array of practical attitudes and our awareness of them in order to make good on the warrant of such knowledge. The same materials are not necessarily available to those who want to argue for a more extensive set of things known without observation. ${ }^{13}$

Now obviously the two views are not necessarily incompatible. After all, these are, arguably, two kinds of knowledge that an agent could have, knowledge of the good and knowledge of their actions, and, arguably, one could call both kinds practical knowledge. But the scholastic view claims that aiming at the good is constitutive of acting, or that the paradigmatic case of action is the expression of practical knowledge as knowledge of the good, and, more generally, that every action expresses what the agent takes to be good, whether the agent is correct or incorrect in what she takes to be good. ${ }^{14}$ So accepting this scholastic view amounts to accepting a certain necessary truth about acting. But the reflectivist view of practical knowledge also postulates a necessary truth about action. So if the two views are independently correct, we have two unconnected properties that actions necessarily instantiate, and thus, of course, two properties that necessarily imply each other without any explanation of their necessary connection. The pure reflectivist strategy to unseat the scholastic view is now clear: find a few apparent counterexamples to the scholastic view, lean on the implausibility of unexplained necessary equivalencies, and watch the scholastic view be either trivialized into an account of an ad hoc subset of proper actions or into an obviously false account of the phenomena. Whatever accounts for the special knowledge we have of our own

13 "Not necessarily" is important here. One could argue that the narrower knowledge presupposes the wider knowledge. See McDowell (2011).

14 This does not prove the existence of knowledge of the good among humans. It only shows that to the extent that such knowledge does not exist, all human actions are defective in at least the sense that they never bring about what they necessarily aim at. 
action accounts for the nature of all and only intentional knowledge, since this feature of intentional actions suffices to specify the class of all intentional actions. Since, ex hypothesi, the scholastic view cannot explicate the truth of reflectivism, it has no role to play in the correct account of intentional action. In sum, if we accept both (a) that the reflectivist has identified a genuine form of knowledge (or belief) that is essential to every intentional action, and (b) that the scholastic view does not imply reflectivism, then the scholastic view at best imposes an arbitrary restriction on the extension of "intentional action."

In the next two sections, I want to examine the plausibility of (a) and (b). The verdict will be the following: (a) needs to be qualified, and (b) is false. This puts the scholastic view at least on a par with pure reflectivism. But this leaves open the question of whether the scholastic view is superior to pure reflectivism. Even if the scholastic view implies reflectivism, it seems to narrow the space of possible intentional actions, and thus the case for the scholastic view seems to depend on whether it can claim some positive advantage over pure reflectivism. In the final section, I argue that the scholastic view can explain important features of action and practical deliberation that are not accounted for by reflectivism.

\section{The Truth of Reflectivism}

There is a long tradition in philosophy of trying to define intention as a form of belief that one will act in a certain way; under such views, to intend to $\phi$ is to believe that one will $\phi$ in a certain way or under certain conditions..$^{15}$ The best-known criticisms of such a view apply to reflectivism; they are simply counterexamples to the view that intending to $\phi$ requires believing that one will $\phi$, or relatedly, that intentionally $\phi$-ing requires believing that one is $\phi$-ing. The classic example of such a kind is Davidson's famous, if antiquated, typewriter example. As I am trying to type 12 carbon copies, I might not believe that I will succeed in making 12 copies. However, it seems that I intend to make 12 copies and that if I succeed I make them intentionally. There are various strategies to deal with this kind of example:

15 See Audi (1973); Davis (1984). 
(a) Restrict the scope of the belief condition - the belief condition does not apply to all of what I intend to do or what I do intentionally but only to some kinds of basic action. ${ }^{16}$

(b) Weaken the attitude, the content, or the generality in question - the belief condition applies to partial beliefs, or the content of the relevant belief is weakened to "it is possible that I $\phi$," or the condition applies onlyto normal or non-defective cases of action. ${ }^{17}$

If we start with Davidson's example, all the above moves seem to handle it well either individually or severally. We can claim that the typer knows/believes that he is typing the letters in the typewriter, or that his credence on the proposition "I am typing 12 copies ..." goes up, or that he must at least believe that it is possible that he is typing 12 copies, or, finally, that, when we fill in the details of the case, any situation in which the agent does not know that he is typing 12 copies would have to be so bizarre that it would necessarily turn out to be a marginal or defective case of action. The view that intention requires belief that it is possible that one will $\phi$ is less problematic for the scholastic view. After all, the scholastic view must say that we act on what we take to be good, but I could not judge that it is good to $\phi,{ }^{18}$ when $\phi$-ing is not a case of something that I judge that I could not possibly do. At the very least, in order to judge that something would be good to do, one must not have too high a confidence that it

16 See Setiya (2008); Davidson himself seems to suggest something along these lines.

17 See Setiya (2008) for the suggestion that we weaken the attitude; see Wallace (2001) for the suggestion that we weaken the content (it is worth noting that Wallace makes the suggestion in a different context). Michael Thompson suggests something like the last disjunct, but he also thinks that Davidson's case is under-described and, when fully described, the successful making of twelve carbon copies would be no more a case of doing something intentionally than winning the lottery (Thompson 2011).

18 Of course, I could judge that it is good if people were to $\phi$, but judging that it is good to $\phi$ is a judgment about what $I$ am to do. 
is impossible to do it. ${ }^{19}$ Now the move to basic action is also helpful, but it is not a general solution to all difficult cases. Suppose my arm has been paralyzed and for some reason I can't see it and I am not very confident that I can raise my arm. I try to raise it, but I do not believe I can succeed. However, if I do succeed, I have raised my arm intentionally. This motivates Setiya to think that the connection between intention and belief is more precisely specified as one of elevated credence. Setiya ends up with perhaps the weakest version of the belief condition on intention that aspires to be fully general:

If $A$ is doing $\phi$ intentionally, $A$ believes that he is doing it or is more confident of this than he would otherwise be, or else he is doing $\phi$ by doing other things for which this condition holds. (Setiya 2008, 391)

Now one can push the example so that it is not even clear that we have elevated credence. ${ }^{20} \mathrm{We}$ might think of someone who is fully confident that his arm is paralyzed, but at the insistence of this beloved wife ("Just try it; for my sake"), tries it and succeeds. Such a person arguably raises his hand intentionally, but his intention does not change his credence. Now I do not want to dwell on such cases, because I think the move to credences represents a much larger concession than it appears. For, obviously the credence in question is not something that the agent is necessarily aware of, and certainly not something that the agent whispers to his mind's ear. But now we need to ask why we should attribute the elevated credence to the agent, an elevation that can be rather minimal. That is, we are now pairing action with the

19 I think that anyone convinced by the Davidson example is not in a position to assert anything more than this. Even requiring that the agent believes that it is not impossible to $\phi$ would seem too strong. Roger Bannister ran a four-minute mile when many scientists thought that it was humanly impossible to do so. In light of this fact, it is perfectly possible that Bannister was not sufficiently confident that it was even possible to run a four-minute mile. Of course, one might argue that, under these conditions, Bannister did not run a four-minute mile intentionally, but it is not clear why one would say this, but at same time accept that Davidson's typer makes 12 copies intentionally.

20 I don't mean to suggest that the following example is decisive against Setiya's view. For a more detailed criticism of Setiya's view, see Paul (2009). For Setiya's response to Paul, see Setiya (2009). 
necessity of a rather ephemeral change in attitude; the agent needs to move from one credence state to another where the difference in confidence can be arbitrarily small. We want to know what warrants our view that intentional action will necessarily be accompanied by this kind of subtle change of attitude. We should ask what exactly about those problematic cases warrants the claim that the agent has adequately changed his credence with respect to the action.

One could try to ground the change in credence in some kind of, say, counterfactual betting behaviour. However, it is unlikely that there is any independent basis to think that an agent in this situation would always have the correct betting behaviour. We might think that it would be rational for the agent to form credences this way, but the claim that the agent does form credences in this way seems more like a bullet to be bitten than a desideratum for an account of agency. ${ }^{21}$ But this brings us to a more general concern about the notion of practical knowledge. Actions are events or processes that extend through time; knowledge is a state. As Thompson et al. emphasize, actions are often referred to in the progressive aspect, ${ }^{22}$ but this is certainly not true of knowledge (Neither of these seem right: *I was knowing"; * "I am knowing.") Although both momentary knowledge and momentary action would be idealizations, they are different kinds of idealization. Momentary action is a degenerate case of progression; momentary knowledge a degenerate case of duration. So it is worth asking, when does the agent know that he is $\phi$-ing? Does she know it in the beginning of, at the end of, or throughout the whole action? Or does this kind of question misconceive the relation between the relevant knowledge and action? Now to claim that practical knowledge only occurs in the beginning or the end of the action is obviously implausible. After all, at least typically, parts of actions are also actions, and

21 In fairness to Setiya, he does try to provide an independent argument for the above principle. But the argument concludes that "just as one cannot intend to do what one is sure one will not do, so one cannot be doing it intentionally with the unqualified conviction that one is doing no such thing" (Setiya 2008, 392). But this argument would at best rule out that the agent form certain beliefs rather than guaranteeing that the agent will form certain beliefs or will adjust credences in a certain way.

22 See Thompson (2008). 
so, if no knowledge is required for most of the actions contained in the larger action, why would it be required for those parts that are at a very specific position in a continuous action?

However to claim that such knowledge is present for the whole duration of action will immediately also send us quickly into the idea that a lot of this knowledge is implicit, and sometimes not easily accessible. ${ }^{23}$ Let us start with a very broad notion of action. We should notice first that almost all actions are "gappy"; that is, not everything that is done while one is $\phi$-ing is a constitutive or instrumental means to $\phi$-ing. ${ }^{24}$ So while I am baking a cake, I can stop to listen to the news, go to the computer and check if I have new e-mail, all this while it remains true that I am baking the cake all the time from beginning to end of the cake. Depending on the cake, I might even have time to take a nap before the cake is baked. ${ }^{25}$ And some other actions will be hard to execute without many moments of unconsciousness between the stages; if I am writing the Great Canadian novel, I'll need spectacular speed or spectacular insomnia to carry out the action from beginning to end without ever falling asleep along the way. So if one is going to argue that I know I am writing the great Canadian novel throughout this process, one needs to say that the knowledge is implicit in a sense of implicit that can be true even when I am asleep, and even when I am so distracted that I would say "no" if asked this question, and even if I would have abandoned the project due to oblivion were it not for my son's reminder that I am writing the Great Canadian novel, etc.

23 Setiya recognizes that practical knowledge must extend much further than what we are explicitly aware of, and he accepts that much of the knowledge in question is implicit knowledge (Setiya 2008). I am not opposed to this move (but see some reservations below). My main contention here is that this changes the nature of the desiderata for a theory of action.

24 For a more precise characterization of gappy actions, see my Tenenbaum (Unpublished manuscript).

25 It is not always correct to say "I am $\phi$-ing" when right now it is one of the gaps in the action. If you ask me: "What are you doing right now," and I say "I am writing my novel," this will strike us as false and misleading if right now I am in front of the TV sipping my beer, and writing a novel is simply something I have been doing for the last ten years. But this does not show that what I say is strictly speaking false; it might simply be a misleading implicature of my assertion. On this issue, see Falvey (2000). 
If we allow for the broad understanding of action, we face the same problem that the move to credence engendered. Given enough theoretical motivation, one can certainly accept that one has knowledge of one's actions even when asleep, forgetful of the action, etc. But we have not identified a desideratum that a view of the nature of action must meet in order not to be dismissed out of hand.

But perhaps what we need is a narrower understanding of action; we might have gone astray in considering that I am writing my Great Canadian novel even when asleep, or that I am still baking a cake while updating my status. A more modest proposal would take no sides on the question of how to demarcate actions, but it would simply limit the claim of practical knowledge to the temporal parts of the action in which one is actually taking means to the action. ${ }^{26}$ It is worth first noting that even the narrower understanding of actions needs to weaken the reflectivist thesis as in (a), but not simply because of the Davidson cases in which I am not confident enough that the means I am taking is effective in bringing about what I intend to do. Suppose I am building a table. I am now carefully working on chiselling a mortise. I am so focused on the task that I can't even remember why I am doing it; even if I were to stop and reflect and it might take me a while to remember why I was chiselling a mortise (I might need to consult my schedule of work and say: "Yes, I am building a table."). It seems that, even in the narrow understanding of action, I am building a table right now, but without relying on a heavyweight notion of implicit knowledge, I can't say that I know that this is what I am doing. The easier path here is to move to the idea that I don't always need to know that I am $\phi$-ing when I am $\phi$-ing, but, to the claim that I need to know of some $\psi$ that I am $\psi$-ing in order to $\phi$ (as proposed by Setiya's definition above).

But it is not clear that even this move will help. For can't I be so used to chiselling mortises that I can do it while talking on the phone or watching TV and lose myself in such a way that I don't even notice

26 This is a bit more complicated since means to an action are also actions, but we can extend the definition further demanding that these means themselves be either non-gappy actions or actions that we are undertaking as means to them. For more on how to distinguish between an active and a "background" pursuit, see my Tenenbaum (Unpublished manuscript). 
that I am still chiselling? We have all had the experiences of driving (or walking) absent-mindedly to the point that if stopped we would not be able to answer the question: "what were you doing?" Again, one might insist that the knowledge is implicit, but here we reach the same point of the dialectic: although those who insist on the truth of reflectivism can make these moves in order to accommodate those cases, there is no independent motivation to accept that for each such case there is some corresponding implicit knowledge of what I am doing.

My aim to examine these marginal cases is, again, not to deny that we typically know our own actions, or even to cast doubts on the importance of this thesis. Rather, I want to understand more precisely under which conditions, and in what way exactly, we know our own actions. And the upshot of our discussion should lead us to the following conclusion: we can find putative counterexamples when we focus on very simple actions (such as stretching one's arm), actions for which a limited set of uncertain means are available, actions which we can perform habitually, and actions which are either in the background, or in which the pursuit of certain means takes on a life of its own. In sum, the reflectivist thesis is at its most plausible when we focus on actions that are relatively long and complex, and whose execution is open-ended, while they are being executed. That is, it would be hard to understand someone who is trying to arrange a meeting but does not typically know what he is doing while he's placing calls, finding places to meet, etc. Moreover, even if these are the only "foolproof cases"; one must grant that knowledge of what one is doing is typically present in all other cases of actions. For most, or at least many, of our simple, habitual, and short actions, and even through the duration of many of the gaps within our actions, we know what we are doing, and a good account of agency should be able to explain this. But if I am right, the scholastic view can do this; or, more precisely, the scholastic view can explain why among the capacities necessary to ascribe to practical knowledge we must include the capacity to (typically) know what one is doing. Moreover, if I am right, the scholastic view cannot only do this, but it can also motivate the claim that we must also have implicit knowledge in those cases in which we seem not even to be dispositionally inclined to affirm that we are $\phi$-ing. 


\section{Scholastic Views and Knowledge of What You Are Doing}

Let us start with a simple argument for the conclusion that a scholastic view cannot explain the necessity of knowing what you are doing from the necessity of doing what one judges to be good. Knowledge of the good or the things that you judge to be good extends to things beyond what you are doing now. So, I might judge that not only is my typing these words good but also calling my parents and preparing lunch for the kids. But if this is so, how would my knowledge of what is good generate knowledge of what I am doing? Wouldn't I need to possess knowledge of an extra premise, an extra premise that cannot be accounted for by the scholastic view? But even if we can answer this simple argument, ${ }^{27}$ this would not suffice to show that the scholastic view could account for the reflectivist claim. For first, knowledge is not closed under entailment, and it would seem that knowledge of one's actions and knowledge of the good are two separate states, and the scholastic view would need to explain why I am always guaranteed to move from one to the other. But more importantly (though relatedly), even if the move from knowledge of the good to knowledge of one's action can be preserved, once we drop the idealization that our actions express knowledge of the good rather than simply what we judge to be good, the problem gets significantly worse. For even if I am wrong about what I judge to be good, the knowledge of my action remains intact, so it seems that knowledge of my actions cannot be explained as a simple consequence of what we judge to be good, given that we want to explain not only that I believe that I am raising my hands when I do so for bad reasons but that I also know in these cases that I am raising my hands. Finally, why couldn't knowledge of the good simply generate the action without my awareness that I am acting? Wouldn't there be at least some actions in which my knowledge of the good can proceed on its own to produce action without my ever becoming aware of what I am doing?28 The scholastic view seems to be committed to taking the reflectivist claim as a brute fact.

27 I argue that only what we actually choose to do counts as our judgment of the good in Tenenbaum (2007).

28 Versions of some of these arguments appear in Setiya (2007). 
Of course, the scholastic view needs to explain not only how knowledge of one's actions is pervasive but also how our actions are known without observation. Whatever one thinks about this kind of knowledge, the reflectivist is certainly right that, when I typically form a belief about what I am about to do or what I am doing intentionally, I do not seem to need to look around and check or go through anything like an explicit pattern of inference from my past forming of intentions to the conclusion that they actually resulted in action.

But at least this aspect of our knowledge of our own action is something that the scholastic view is in a good position to explain. For insofar as I can make decisions about how I will act, I should be able to think, justifiedly, that at least for some basic actions, my setting myself to do it suffices for my doing it. Otherwise, acting would be an infinite regression of looking for further and further means in one's practical deliberation. Coming to the provisional conclusion that $\phi$-ing is good would set up the question of how to $\phi$, and if we would conclude that it would be good to $\phi$ by $\varphi$-ing, we would need to answer how we would $\varphi$ and so forth. Thus setting oneself to do certain basic actions would suffice, at least in typical cases, for knowledge that one is doing it or will do it.

This, of course, assumes that we are aware of our evaluative judgments, but one might protest that the scholastic view gives us no reason to think that we should be always (or typically) aware of such judgments. But there is an obvious way that the scholastic view would require that it is a condition of intentional action, at least intentional action that is characteristic of human agents, that, at least typically, we know what we are doing. Of course, if we are thinking of an agent pursuing one thing at a time, there is no reason why her evaluative judgments would not just control her body without her awareness of what she is doing. But human agents have multiple ends, and they are guided in their pursuits by a more general conception of the good that will include a number of actions, projects, commitments, etc. ${ }^{29}$ In every circumstance of choice, and in the process of performing every action, any of my other pursuits could become engaged, and, ideally, an agent would have all such actions and projects in mind whenever

29 A more detailed account of this aspect of the scholastic view is presented in my Tenenbaum (2007). 
acting. Although we do not live up to this ideal, it is hard to see how an agent could pursue a complex conception of the good of this kind without being aware of what he is doing at least most immediately. In particular, I need to evaluate my reasons as reasons and thus I need to know what I am doing intentionally. If am carrying water to my house, I need to know that I am not stepping on a sacred burial place, that I am not missing out on the opportunity to buy the well near my house that would make this journey unnecessary, that my leisurely pace is compatible with my getting to my brother-in-law's party, etc. In particular, I need to know the comparative importance of the various ends that I am pursuing and that I could be pursuing in this action. But I can evaluate my reasons for doing what I am doing only if I am aware of what I am doing intentionally. That is, I can only know that I should keep writing my novel rather than practising my video game skills, if I know that what I am doing is writing my novel, rather than typing random words at the keyboard. In order to be the kind of agents that act from knowledge of the good we must (typically) know not only the bodily movements we are performing but the reasons why we are performing them; in other words, we need to know what we are doing intentionally.

This account fits precisely the kind of knowledge of one's actions that we actually find in agents; the knowledge is most clear present with respect to actions that are most immediately being undertaken and need not be more than implicitly present when performing tasks which I can undertake without fear that they'll conflict with other actions (very short or actions that I am very adept to perform well without monitoring the environment and that are unlikely to interfere with other pursuits), etc. Rather than being surprising, knowledge of our own actions has exactly the structure we would expect if practical knowledge were as described by the scholastic view.

\section{Moore's Paradox: Theoretical and Practical}

So far we have at best defended the scholastic view of practical knowledge against a potential threat, but we have given no positive support for it. Why should we think that in order to act you need to have views about the good, rather than just, for instance, being aware of the (explanatory) reason why you did it? Perhaps at this point, what 
separates the scholastic view from the pure reflectivist view can be put as follows: both views agree that in order for something to count as an action, the agent must be capable of providing an answer to the question: "Why are you $\phi$-ing?," in the special sense of the "why" question that Anscombe identifies. However, for the advocate of the scholastic view, this answer is supposed to specify why the agent saw the action as good. Meanwhile, the pure reflectivist thinks that the answer does nothing of this sort: it simply gives either the explanatory reason, or, perhaps, it simply explains how one was (consciously) doing something by means of doing something else. So the scholastic view would ideally be able to identify something about the structure of action that would motivate the more substantive conception of action she's proposing. Again, for the scholastic view, the good stands to action in the same way as belief stands to truth.

Although a proper defence of this claim would require much more work, here I'll make the following proposal: one cannot understand the constitutive relation between belief and truth as merely a normative relation. To believe that $p$ is not simply to be in a state that is correct if and only if $p$ is true; 30 to believe something is also to hold it to be true, or to accept its truth. Again, one needs to make this thought much more precise, ${ }^{31}$ but even in this rough formulation we can see its appeal by considering the problematic nature of Moore's paradox. It is hard to explain what goes wrong by asserting propositions that are Moore-paradoxical if we think that the relation between belief and truth is merely normative. ${ }^{32}$ A subject who simply said "It's raining, but I don't believe it," or, better, "I believe it is raining, but it is not raining" would simply be reporting her own state of non-conformity with a norm. This would be, perhaps, a sad state to find oneself in, but certainly not an impossible one. It's only if belief is one's final stance on what is the case that we can think of the Moore-paradoxical sentence as expressing contradictory states; the first conjunct states the denial

30 See Shah (2003) and Shah and Velleman (2005). I'm not denying that this might also be true of belief; all I am claiming is that this cannot be the full account of the relation between belief and truth.

31 I do a bit more in Tenenbaum (2007).

32 For a detailed discussion of the difficulties of explaining Moore's paradox along these lines, see Heal (1994). 
of what the second conjunct expresses. Similarly if someone pays you millions of dollars to believe that $2+2=5$, you can't simply say: "I'm all for the norm of truth, but this is a lot of cash; just this once, I'll set it aside." You can't do this even if you are a great lover of money, or even as some bizarre form of akrasia. Obviously there is much more to say about Moore's paradox, the impossibility of believing at will, and about the relation between belief and truth. The only point that I want to press here is that there are dim prospects for understanding the relation between belief and truth as merely normative; belief must be somehow one's stance towards what is the case and not merely a stance that one ought to have towards what is the case.

If we agree with this point, we can ask whether there are similar phenomena in the case of action. Are there similar paradoxes that are generated by trying to pry apart action and the agent's conception of the good? Can we see a similar contradiction in supposing that the agent acts but does not judge something to be good? At first blush, it would seem that, if anything, the pure reflectivist can score a significant victory on this field. For it seems that, far from being an impossibility, it is a rather common occurrence; people often seem to be acting in ways that they do not judge to be good. One need not be a great villain to act from time to time in such a way that one recognizes is shameful or corrupt. The problem with such examples, however, is that "good" is said in many ways. The scholastic view claims that a formal notion of good, a notion, roughly, of getting things right in practical deliberation, plays an essential role in our understanding of something as a case of intentional action. But this should not be confused with the obviously false claim that a more substantive notion could play the same role; our actions do not always express our judgments of what is morally good (when morality is narrowly conceived) or of what is healthy ("I' $\mathrm{I}$ being so good; I haven't eaten chocolate in two days.").

Still, an adequate account of the scholastic view needs to explain how it can accommodate the obvious possibility of acting akractically, perversely, etc. But since a great deal work has been done in this direction, I'll leave this aside and boldly assume that there is out there in the philosophical world a satisfactory account of all these phenomena within the scholastic framework. ${ }^{33}$ This still would leave

33 For my own views on how these phenomena are compatible with the scholastic view, see Tenenbaum $(1999 ; 2003 ; 2007)$. 
us at best indifferent between scholastic and pure reflectivist views, unless we can identify Moore-paradox-like phenomena in the realm of action.

But I think we can. In fact, I think the toxin puzzle, ${ }^{34}$ for instance, is exactly such a case. In the toxin puzzle, someone who has some kind of reliable way of knowing when someone forms an intention offers me a million dollars today to form the intention to drink "toxin." Toxin has no lasting effects but will make me feel quite miserable for a day. It won't make me feel so miserable that it would not be worth the million dollars; in fact, given the choice, I would gladly take the toxin for a million dollars. But this is not the choice that I'm given; I'll get the million dollars if I intend to drink the toxin, whether or not I drink it. Although this might appear to be a sweeter deal, most philosophers agree that in this case the money is not within my reach. ${ }^{35}$ Given that I know that tomorrow I'll already have the money, I know that tomorrow I'll have no reason to drink the toxin. And thus I know that I won't drink the toxin tomorrow. But under these conditions, I cannot form the intention to drink the toxin, or so it seems. But the question then is why not? Given the immense benefits of forming the intention (I would be ready to drink it, let alone to drink it for a million dollars), why can't I just do it?

Two things are worth mentioning about the toxin puzzle for our purposes. First, it's crucial that I assume that tomorrow, I will judge that I will not have good reasons to drink the toxin. It would be "cheating" to meet Kavka's challenge by stipulating in the fact that I want to show my stoicism in the face of misery to my beloved, or that I promised a friend to give him a million dollars if I didn't drink the toxin, etc. Second, although the puzzle is often presented as hanging on the relation between future-directed intention and action, a version of the puzzle can be constructed that mentions only actions. Suppose the same person will pay me the same amount of money if I am baking a Black Forest cake at 10 a.m. tomorrow, and he doesn't allow me to start baking the cake before 9:45 a.m. He recognizes that it takes more than fifteen minutes to bake such a cake, but he does

34 One feels it barely necessary to mention the source of this case: Kavka (1983).

35 Most but not all. See, for instance, Gauthier (1998). 
not care whether there's a cake at the end of the day. As long as I am baking a Black Forest cake at 10 a.m. he'll pay up. Suppose I don't like baking cakes, especially those parts of the process that come after the first fifteen minutes. But obviously I don't dislike it so much that it's not worth a million dollars. However, I am in the same predicament as Kavka's agent in the toxin puzzle. After all, in order to be baking a cake at 10 a.m. I must expect that there'll be cake at the end of the process, or at the very least I must not be too confident that there'll be no cake at the end. But given that I know that, once I get the money, I'll have no reason to keep baking a cake, I know that there'll be no cake, and most likely not even batter, at the end of the process. So whatever I am doing at 10 a.m., it's not baking a cake. And notice that analogously to the case of toxin, it's not that my action couldn't count as baking a cake unless there's cake at the end; through bad luck, laziness, or incompetence, baking a cake often fails to deliver on its promised result. Yet, in such cases, it is still true that I was baking a cake even though no cake was ultimately baked. ${ }^{36}$ All that I need is to have a baked cake as my end. But again, we can ask the same question: given that I obviously would rather be baking a cake than forgo a million dollars, why can't I just make it my end, even for a few minutes, to bake a cake?

The scholastic view has an answer to these questions that is analogous to how I suggested one should approach Moore's paradox. Acting (or forming an intention) is the expression of judging that $\phi$-ing is good. (I'll just call it an "evaluative judgment" from here on.) The assumptions of the toxin puzzle, in its original or in my revised version of it, guarantee that I form a certain evaluative judgment but calls for me to act in such a way that expresses an incompatible judgment. That is, the claim that I am persuaded that there'll be no good reason to drink the toxin or to bake the cake, it is, on the scholastic view outlined above, just being persuading that $\phi$-ing is not good. But at the same time, according to the scholastic view, baking the cake would express the judgment that it is good to bake a cake, but this is obviously incompatible with the previous evaluative judgment. So in both versions the agent is being asked to be persuaded that something is good, when, ex hypothesi, we know that he is persuaded that it is not

36 On this point, see Thompson (2008). 
good; and to be persuaded that something is good in these conditions is indeed really difficult. ${ }^{37}$

Can the pure reflectivist account for the impossibility of forming the intention or acting in the toxin cases? Setiya claims that the toxin puzzle is just a consequence of the principle that intention requires belief: given that I do not believe that I'll drink the toxin, I cannot intend to drink it. ${ }^{38} \mathrm{~A}$ similar line could apply to our baking the cake case. However, the question is: exactly why can't I form the belief? After all, for those things that I can do in the conditional sense of "can do," 39 practical knowledge requires that my intention or action justify my belief, not the other way around. I could be justified in believing that I will drink the toxin by forming the intention to drink the toxin. But the problem is that I can't, and our question was why, according to pure reflectivism, can't I? We can make the problem more pressing by looking at a reflectivist position like Setiya's. According to Setiya, an intentional action is an action done for a reason, but not a reason in the normative sense of "reason," but in the explanatory sense of "reason." That is, when I choose to act, I must choose to act on a reason, but I need to choose to act on a good reason. 40 But in this case choosing to drink the toxin tomorrow should be an easy accomplishment; my reason can even be "so that I'll get the money." Obviously getting the money is not a good reason to drink the toxin; that was our predicament to begin with. But the whole point of pure reflectivism is that we need not choose that which we judge to be good. And in fact, this seems to be a great

37 One might complain that it would be really difficult but not impossible. After all, why couldn't we be persuaded of contradictory things? This is an incoherent but not impossible set of states. But if this is the case, we need to add to the picture a further judgment from the agent to the effect that drinking the toxin is good, a judgment that would probably (or certainly, in my view, see Tenenbaum, 2007) be based on some way of conceiving the action of drinking the toxin to be a good action in this context. But this is exactly what the example stipulatively rules out.

38 Setiya (2008).

39 That is, "I will $\phi$ if I choose to $\phi . "$ Setiya (2007) also uses this conditional sense of the ability to do something.

40 See, for instance, Setiya (2010). 
opportunity to do so: acting on a bad reason can earn you a million dollars. Moreover, if there is something that makes us akratic, it is exactly the trade-off between cash and some future evil. But in fact we don't even expect this would be one of those rare cases in which one is fortunate for being akratic. Rather, if we think about how the agent is most likely to come to drink the toxin, it is exactly by being somehow persuaded that it would be good to drink the toxin tomorrow (perhaps by reading philosophy papers defending the position that one ought to drink the toxin).

Of course, this kind of pure reflectivist can say that, even though actions can be done for any explanatory reason, normative reasons and choosing what is good are, well, normative for us, and thus we cannot simply choose not to do what there's most reason to do. But there are important problems with this answer. First, it is not clear what it means to say that this is "normative for us." Is this a norm among many or a decisive norm? And isn't it a norm that sometimes we violate? After all, if we accept that we never violate this norm, or even that at least we are always trying to follow this norm, then it seems that we have accepted that we always choose what we take to be good, and we have thus accepted the scholastic view. The pure reflectivist could say that it is possible to violate the norm, but we cannot choose to do so; we cannot do this intentionally. But this quickly collapses into the first point; for it says that, although we can act in such a way that we are not pursuing the good, we cannot do this by trying to act in such a way that one is not choosing what one judges to be good; we can only do so accidentally. But doing something accidentally is not doing it intentionally, and if you cannot $\phi$ by trying to $\phi$, you cannot $\phi$ intentionally. That is, if you cannot ride a bike by trying to ride a bike, but only if you are accidentally riding a bike, then riding a bike is not something you can do intentionally. But if you cannot choose to act in such a way that you are not choosing what you take to be good intentionally, that means that whenever you choose intentionally you choose as you judge to be good. We are once again happily endorsing the scholastic view.

If the argument is correct, the scholastic view, first, provides at least as good an account of knowledge of one's action as pure reflectivism, and in fact it does better at explaining the extent of our knowledge of our actions than pure reflectivism, even though pure reflectivism 
takes these phenomena as its starting point. Moreover, the scholastic view can explain why there are purely rational limits to acting.

Of course, this line of argument does not show that the scholastic view is superior to views that postulate a different constitutive or formal end of action. If a view, for instance, claims that desire satisfaction is the formal end of acting, then it might be able to avail itself of a similar explanation. And, in some views, the constitutive aim of agency might be connected to the reflectivist claim in such a way that makes these views, arguably, versions of pure reflectivism; for instance, in David Velleman's view, the constitutive aim of agency is autonomy or the conscious control of our actions. ${ }^{41}$ However, even if the connection between reflectivism and the constitutive aim of agency is more immediate in certain views, this is not, on its own, an advantage over the scholastic view, as long as the truth of reflectivism is also explained by the scholastic view; and I hope to have shown that it is.

Moreover the ability of these other constitutive aims to explain phenomena like the toxin puzzle will depend on whether they can show as easily as the scholastic view why it is impossible to form the relevant intention. It might appear obvious that the desire satisfaction view can simply appeal to the fact that I will have no desire to drink the toxin or continue to bake the cake, but this is not true. After all, at the time in which I need to form the intention, I'd prefer to receive the money over not drinking the toxin or not baking the cake. Of course, the advocate of such a view might want to appeal here to the very principle that intention presupposes belief and that the agent knows that not baking the cake or not drinking the toxin will soon become her most preferred option. However, here the criticism that misfired against the scholastic view, seems right on the mark: the advocate of the desire satisfaction view would be appealing here to a view that he is in no position to explain. Velleman's autonomism, of course, has no problem in explaining why intention requires belief, and one can argue that the view can just as well appeal to the constitutive goal or aim of agency as a way of explaining why the agent cannot simply choose to drink the toxin and bake the cake. However, it is far from clear that given the thinness of the aim of autonomy, one could easily

41 See Velleman $(1989 ; 2000)$. 
show that this is not possible; why can't the agent who aims at the conscious control of her behaviour do it by having drinking the toxin as her substantive aim?

I obviously do not intend these last remarks to settle the issue. There are various things that the advocate of the desire-satisfaction view, and even more so the "autonomist," could try to say in response to these concerns. My aim in the paper was not to establish that the scholastic view is the only theory of agency that can properly account for the phenomena discussed here. Rather, my aim was to argue against thinking that a theory of agency has a single master to obey, a single essential feature to account for: the special kind of selfconsciousness characteristic of the way we know what we are doing. Thinking of a theory of agency in this manner is likely to raise difficulties for a scholastic theory, since it will make it seem like an attempt to restrict in an arbitrary manner the range of things that fall under the concept "intentional action." However, if I am right, the special selfconsciousness of action is not the only thing that a theory of agency must account for; any theory of agency must also explain why this self-consciousness has a special kind of "orientation" too. It is, just like the self-consciousness of theoretical judgment, consciousness of the exercise of a capacity to "get things right" in some way. And it turns out that the scholastic view is in a particularly good position to account for both these essential features of agency. However, it is certainly not possible to show here that it is the only theory of agency that can do so.

\section{References}

Anscombe, G.E.M. 1963. Intention. Ithaca, NY: Cornell University Press.

Audi, R. 1973. "Intending." Journal of Philosophy 70: 387-403.

Davis, W. 1984. "A Causal Theory of Intending." In The Philosophy of Action, ed. A. Mele,131-48. Oxford: Oxfod University Press.

Falvey, K. 2000. “Knowledge In Intention." Philosophical Studies 99, 1: 21-44.

Gauthier, D. 1998. "Rethinking the Toxin Puzzle." In Rational Commitment and Social Justice: Essays for Gregory Kavka, ed. J. Coleman and C. Morris, 47-58.Cambridge: Cambridge University Press.

Heal, J. 1994. "Moore's Paradox: A Wittgensteinian Approach."Mind 103, 409: 5 . 
Kavka, G. 1983. “The Toxin Puzzle.” Analysis 43, 1: 33.

McDowell, J. 2011. "Anscombe on Bodily Self-Knowledge." In Essays on Anscombe's Intention, ed. A. Ford, J. Hornsby, and F. Stoutland. 128-46. Cambridge, MA: Harvard University Press.

Paul, S. 2009. "Intention, Belief, and Wishful Thinking: Setiya on 'Practical Knowledge'." Ethics 119, 3: 546-57.

Setiya, K. 2007. Reasons without Rationalism. Princeton, NJ: Princeton University Press.

—. 2008. "Practical Knowledge." Ethics 118, 3: 388-409.

- 2009. "Practical Knowledge Revisited."Ethics 120, 1: 128-37.

- 2010. "Sympathy for the Devil." In Desire, Practical Reason, and the Good, ed. S. Tenenbaum, 82-111. New York: Oxford University Press.

Shah, N. 2003. "How the Truth Governs Belief." Philosophical Review 112, 4: 447.

Shah, Nishi, and David J. Velleman. 2005. "Doxastic Deliberation." Philosophical Review 114, no. 4: 497-534.

Stocker, M. 1979. "Desiring the Bad: An Essay in Moral Psychology." Journal of Philosophy 76: 738-53.

Tenenbaum, S. 1999. “The Judgment of a Weak Will." Philosophy and Phenomenological Research 49, 4: 875-911.

- 2003. "Accidie, Evaluation, and Motivation." In Weakness of Will and Practical Irrationality, ed. S. Stroud and C. Tappolet, 147. Oxford: Oxford University Press.

- 2007. Appearances of the Good: An Essay on the Nature of Practical Reason. Cambridge: Cambridge University Press.

—. Unpublished manuscript. "Reconsidering Intentions."

Thompson, M. 2008. Life and Action. Cambridge, MA: Harvard University Press.

- 2011. "Anscombe's Intention and Practical Knowledge." In Essays on Anscombe's Intention, ed. A. Ford, J. Hornsby, and F. Stoutland. Cambridge, MA: Harvard University Press.

Velleman, J. D. 1989. Practical Reflection. Princeton, NJ: Princeton University Press.

- 1992. "The Guise of the Good."Noûs 26, 1: 3-26.

2000. "The Possibility of Practical Reason." In The Possibility of Practical Reason, 170-99. New York: Oxford University Press.

Wallace, R. 2001. "Normativity, Commitment, and Instrumental Reason." Philosopher's Imprint 1, 3: 1-26. 